\title{
Análisis ético de la publicidad de los créditos al instante en España
}

\author{
Manel Vinyals* \\ Álex García** \\ Recibido: $x x x x x x x x x x x$ \\ Aceptado: $x x x x x x x x x x x x x x x x x x$
}

\section{RESUMEN}

Poco antes de que estallaran en Estados Unidos una serie de productos financieros de alto riesgo como los créditos subprime y se desencadenara una inevitable crisis bancaria a escala mundial, asistimos en España, durante los años 2006 a 2008, al auge de una modalidad de concesión de créditos con unas características, condiciones y circunstancias que analizaremos en este artículo desde el punto de vista ético y normativo.

Palabras clave: ética, publicidad, créditos al instante, España.

* Manel Vinyals i Corney, profesor de la Universidad Autónoma de Barcelona. Facultad de Ciencias de la Comunicación. España. Correo: manel.vinyals@uab.es

** Álex García, licenciado en la Facultad de Ciencias de la Comunicación. Universidad Autónoma de Barcelona. Correo: alex. garcia@campus.uab.es 


\title{
Ethical Analysis of Publicity of at Instant Credits In Spain
}

\begin{abstract}
Just before a range of high risk financial products appeared in the United States, such as subprime credits, and an unavoidable worldwide banking crisis unleashed, from 2006 to 2008, we witnessed, in Spain, the boom of a credit concession modality with characteristics, conditions, and circumstances that will be analyzed in this article from an ethical and regulatory point of view.
\end{abstract}

Key words: Ethics, advertising, instant credit, Spain. 


\section{INTRODUCCIÓN}

Poco antes de que estallaran en Estados Unidos una serie de productos financieros de alto riesgo como los créditos subprime y se desencadenara una inevitable crisis bancaria a escala mundial, asistimos en España, durante los años 2006 a 2008, al auge de una modalidad de concesión de créditos con unas características, condiciones y circunstancias que analizaremos en este artículo desde el punto de vista ético y normativo.

Los índices de situación económica en España reflejan una recesión, evidenciada desde finales del año 2008 y que se ha reafirmado en el año 2009. Las previsiones de recuperación se realizan con mucha cautela; y entre los muchos sectores económicos que se están reorganizando, podemos encontrar la banca y un sistema financiero que había pecado de ciertos excesos, sobre todo en la concesión de créditos de una forma un tanto indiscriminada.

Durante muchos años, tradicionalmente, las únicas entidades que concedían préstamos a particulares y a empresas eran los bancos y cajas de ahorros; aunque legalmente, pero con una regulación escasa, existía la posibilidad de créditos de consumo por empresas o particulares que no pertenecían a la jerarquía financiera propia de los bancos y cajas. Para la mayor seguridad de las operaciones y con el objetivo de evitar riesgos innecesarios, estas entidades financieras pedían unas garantías que determinadas personas y pequeñas empresas no podían aportar; y de este hueco de mercado surgió la visión de algunas empresas, de ofrecer a particulares créditos con una serie de ventajas como rapidez, inmediatez, facilidad y simplificación de trámites, que pronto conllevaron la creación de un nuevo sector, en medio de las entidades financieras tradicionales y la posibilidad privada de créditos entre particulares.

La primera empresa de este tipo que se estableció en España fue la francesa Cofidis hace quince años, y durante los años 2006 a 2009 operaron en el mercado español las empresas cuya publicidad analizamos en este estudio: CrediÁgil, Cityfinancial, Credit CB Servicis, Credial, Accordfin, Broker's Finance, Cetelem, Citi Financial, Creditotal, Freedom Finance, Gestocredit, Imagina, Mediatis, Via Hipotecaria y Viva Line. En general, todas planifican su publicidad en prensa, fundamentalmente la prensa gratuita, radio y televisión. Además de ello, todas tienen página web, y ha sido útil poder comparar la información sobre los elementos persuasivos utilizados en la publicidad a través de los medios convencionales, y contrastarlo con las posibilidades informativas del medio Internet.

Una de las características de esta publicidad es su planificación en soportes (prensa gratuita, franjas horarias en radio y televisión de mañana, etc.) directamente relacionadas con un público objetivo muy concreto: amas de casa, personas sin trabajo y que buscan trabajo, personas jubiladas, etc.

Este trabajo se ha desarrollado en distintas fases: en la primera, y tras distribuir las marcas entre los participantes, se hizo una primera prueba de análisis de cada anuncio; en la segunda se sistematizaron y uniformizaron los criterios de valoración de los anuncios para poder extraer conclusiones; y en la tercera fase se extrajeron los elementos comunes, se computaron las variables que se podían medir, para llegar a ciertas conclusiones en cuanto al análisis de la publicidad, tanto en el plano formal, como de criterios de tipo ético.

\section{OBJETIVO DE LA INVESTIGACIÓN}

Esta investigación se propone un objetivo principal y distintos objetivos complementarios. El objetivo principal es analizar hasta qué punto la publicidad de estos productos puede inducir a error a los consumidores -destinatarios-. De este modo, el análisis ético está en el punto central 
de la investigación, aunque se pretende llegar a una valoración de tipo ético paulatinamente, sin forzar ninguna interpretación ni precipitar ninguna conclusión.

Para complementar, el primer elemento metodológico fue trabajar distintos modelos y propuestas de análisis que nos sirvieran para radiografiar la publicidad. Después de haber consultado distintas investigaciones y bibliografía, constatamos que no existe un modelo completo y estandarizado de análisis de la publicidad. Por lo tanto, partimos de esta situación de dispersión y tratamos de trabajar, inicialmente, con análisis individuales realizados por un grupo de codificadores que reflejaran la visión de cada investigador, para, en una segunda fase, formular un modelo completo y uniforme a partir del cual volver a analizar todos los mensajes y empezar la fase de análisis y conclusiones.

Los objetivos de esta investigación han sido pioneros respecto el análisis de la publicidad de esta actividad comercial, puesto que el trabajo se inició un año antes de que el gobierno de España anunciara su intención de regular este tipo de actividad porque estaba empezando a generar problemas, especialmente los derivados de las elevadas comisiones, intereses y el abuso en la ejecución de unas garantías que, en muchos casos, comportaban la pérdida de viviendas y bienes inmuebles de personas que reconocían haber sido muy poco informadas de estas consecuencias.

\section{METODOLOGÍA}

Las fases de la investigación se proponían partir del conocimiento previo del equipo de codificadores para analizar exhaustivamente un tipo de anuncios bien delimitado; con identidad en cuanto a tipología de anunciantes, productos y marcas que han aparecido, bajo denominaciones similares, durante estos últimos 5 años y, fundamentalmente, con una publicidad muy similar tanto en el ámbito formal como en el argumental.
Toda la publicidad seleccionada realiza propuestas del mismo tipo a un tipo también bien delimitado de posibles consumidores.

\section{ANÁLISIS}

La ética de la publicidad es algo que, de entrada, parece demasiado abstracto como para centrar un análisis basado sólo en ella. Por ello, planteamos organizar una investigación que permitiera extraer, a través de distintas fases, elementos que pudieran tener una valoración de tipo ético y deontológico, además de jurídico o legal.

Por lo tanto, no se empezó por un análisis de tipo ético, sino por un análisis de la publicidad desde el punto de vista descriptivo. Con ello, se podía delimitar un elemento que también puede ser complejo: ¿dónde empieza y acaba la responsabilidad de una agencia con respecto a la que corresponde al anunciante?; ¿se puede desvincular una agencia de publicidad totalmente respecto a la actividad profesional de quienes le encargan que busque los mensajes que llamen la atención y convenzan a las personas para que les tengan en cuenta, compren, consuman, etc.?

Después de recopilar los diversos análisis éticos de cada anuncio, hemos extraído ciertas informaciones valiosas para llegar a una conclusión. El análisis se ha realizado parte por parte, a través de los apartados Análisis ético, Análisis de los conceptos publicitarios y Análisis connotativo.

\subsection{Análisis ético}

\subsubsection{Aspectos no éticos}

Uno de los ítems analizados incide sobre los aspectos no éticos que se reconocen en los anuncios, y encontramos que en la mayoría existe una falta de información, ya sea a través de ocultar datos importantes como condiciones bancarias o modificando la información (exagerando o escon- 
diendo contraprestaciones). De todas maneras, al amparo de un vacío legal, estas empresas son conscientes de que tienen un amplio margen de actuación, y de que este vacío legal les ofrece un amplio margen de movimiento, sea o no sea ética su actuación.

De las 16 empresas de créditos fáciles analizadas, en la publicidad de 11 de ellas se comprueba una falta de información, especialmente la relativa a las condiciones de contratación y bancarias. Ver figura 1.

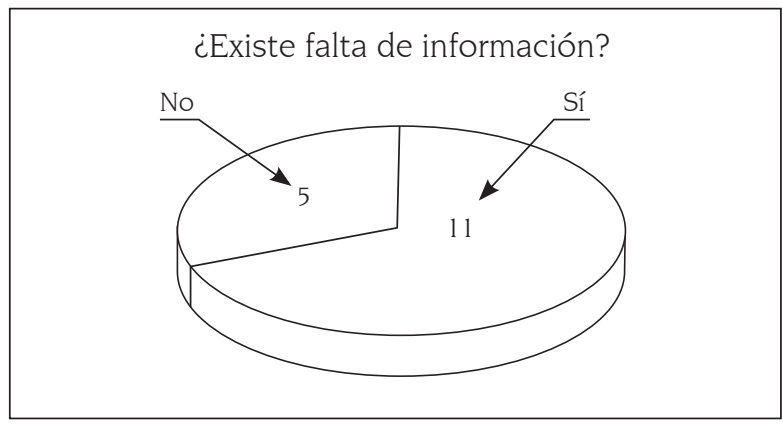

Fig. 1. ¿Existe falta de información?

En algunos casos, con tal de cumplir la normativa, los anuncios indican las condiciones básicas del contrato en una letra muy pequeña, que impide su percepción y lectura.

Otro aspecto no ético consiste en la realización de exageraciones y promesas que en la realidad son difíciles de cumplir. Destaca el hecho de que se utilizan en numerosas ocasiones personajes que hacen la función de testimonios, para dar credibilidad a la empresa.

\subsubsection{Elementos publicitarios}

Se puede observar, en este apartado, que el aspecto más valioso, a la hora de valorar cuáles son los elementos publicitarios correctos, se basa en la transparencia.

Así, el concepto transparencia puede transmitirse de distintas maneras, pero siempre de un modo que aporte credibilidad por parte de la marca. En los casos analizados, encontramos que uno de los aspectos más valiosos es el de informar, simplificar al máximo las promesas y limitarse a informar, a través de la explicación objetiva de las ventajas del servicio, la inclusión de información de contacto y la información económica detallada.

Por otro lado, observamos que se valoran positivamente los aspectos formales y de diseño de las piezas publicitarias. Con esto nos referimos al tamaño de los objetos, al color de las tipografías, el uso de los colores corporativos y el uso de imágenes y fotografías que seduzcan al receptor.

\subsubsection{Elementos que inducen a error}

En este apartado se analizan aquellos elementos incluidos en las piezas publicitarias, que no son transparentes y que pueden inducir a error.

En primer lugar, encontramos el principal problema, que es la falta de información o el hecho de dar la información de manera parcial. Por ello, se debería añadir toda aquella información relativa a la información económica (condiciones, intereses, mensualidades, cuotas, trámites, plazos, etc.).

Por otro lado, detectamos ciertas dificultades a la hora de analizar los eslóganes y bodycopies existentes, sobre todo en las piezas gráficas. En muchos casos se asegura la libertad total por parte del usuario para elegir la cantidad económica, la duración y las condiciones a la hora de devolver el dinero. En general, este hecho suele ser incorrecto, ya que se contradice con otras normas que aparecen en letra pequeña o bien que el usuario descubre una vez contratado el servicio.

También existe un tipo de promesas que incluyen las expresiones "desde" (desde 3.000 euros) y "hasta" (hasta 48 meses). Este tipo de frases suelen inducir a error, aunque en apariencia puedan parecer correctas, porque no se especifican las 
condiciones que permiten la adquisición del servicio tal como indica el anuncio.

Finalmente, es destacable el uso que se hace de personajes testimoniales, que corroboran la información aportada por la marca, sin siquiera saber el nombre del testimonio ni su experiencia real con la empresa. Todo ello resta transparencia y, por tanto, credibilidad al servicio prestado. Otro aspecto relacionado con la no identificación de los testimonios es el hecho de no indicar las fuentes que objetivamente califican a una determinada empresa como la número 1 o como la mejor. Si no se indica de dónde se ha extraído la información, se convierte en un elemento que induce a error.

Todos estos aspectos mencionados se convierten, pues, en aspectos considerados no éticos a la hora de realizar anuncios de créditos fáciles.

\subsubsection{Valoraciones en escala}

Ante preguntas relacionadas con la omisión de información, se han confeccionado unas conclusiones numéricas que indican el grado de acierto de las marcas que prestan el servicio, siendo 1 el valor mínimo y 10 el valor máximo.

Las dos primeras cuestiones buscan encontrar el origen de aquellos elementos que inducen a error, a causa del mensaje en sí o de la estructura del anuncio, de manera que podamos adjudicar responsabilidades dependiendo de quién ha cometido la falta.

La valoración media sobre si el mensaje puede inducir a error es de 5,9. Observamos pues, un elevado porcentaje que indica un fallo en la elaboración del mensaje. Acerca de la inducción a error causada por la estructura del anuncio, encontramos que posee una valoración de 5,0. Así, a pesar de ser también una cifra elevada, se demuestra que el fallo en la transmisión de información viene más dado por el mensaje realizado por la marca que por la estructura del anuncio, construida por la agencia de publicidad.

Para profundizar acerca de la intencionalidad de la falta de información, analizamos la pregunta: "¿Eres consciente de la información que se omite?". Así, encontramos una media del 6,7. Ello demuestra que, con una simple ojeada al anuncio, el receptor será capaz de descubrir la existencia de falta de información.

La pregunta creada a modo de conclusión es directa: "¿Calificarías este anuncio de publicidad engañosa?". La media obtenida es de 6,1. Por tanto, descubrimos que la mayoría de anuncios de créditos fáciles contienen publicidad engañosa, de un modo u otro.

\subsection{Análisis de los conceptos publicitarios}

\subsubsection{USP, Beneficio y Reason Why}

Este apartado pretende analizar cuáles son los objetivos publicitarios de los anunciantes, a través del mensaje que pretenden transmitir, con su beneficio y su promesa.

El primero de estos elementos, la USP, busca conocer cuál es la proposición de compra que se quiere potenciar y transmitir a los públicos.

En tanto que se trata de créditos fáciles, las características que más se potencian en la publicidad son las relacionadas con la rapidez y la facilidad. La mayoría de piezas aseguran inmediatez en el préstamo (algunos de los titulares utilizan la expresión "en 24 horas"), a la vez que facilidades para conseguir dicho préstamo, sin ningún tipo de problema y sin tener que justificar para qué se pide el préstamo.

El segundo concepto más utilizado en la USP es el de ahorrar dinero (especialmente a través 
de la unificación de deudas), donde a través de la publicidad algunos anuncios acaban afirmando que con ellos ganas dinero.

Finalmente, el otro recurso más utilizado es el de la cantidad. Si en la mayoría de empresas, la cantidad económica que conceden es un máximo de 3.000 euros, en algunos casos llegan a conceder hasta 6.000 o incluso 30.000 euros. Esta diferencia competitiva es otro aspecto que unas pocas empresas utilizan.

En cuanto al beneficio, la mayoría de conceptos seleccionados coinciden con aquellos que propone la USP. Así, volvemos a ver que los beneficios más utilizados son la inmediatez y la sencillez. En algunos casos van más allá y aseguran comodidad o incluso seguridad.

Otras empresas han decidido indicar el beneficio del ahorro de dinero, es decir, pagar menos intereses mediante la agrupación de los préstamos.

Pero, mayoritariamente, los beneficios transmitidos son los que hemos indicado más arriba, porque son directos y son dos de los aspectos que más interesan a los públicos.

Si nos centramos en la Reason Why o demostración creativa de los anuncios, observamos que la promesa se sostiene a través los ejemplos utilizados en los anuncios, generalmente testimonios. El concepto más utilizado es el de la felicidad, aplicado de distintas formas. Es decir, se confirman los beneficios diciendo que el público obtendrá la felicidad que buscaba, a través de demostraciones con personajes que ya han conseguido su objetivo y son felices.

En otros casos, se justifican los beneficios de una manera muy gráfica: utilizando el chasquido de dedos o usando un reloj (como dice la expresión "en un tic tac"). De todas maneras, ambos conceptos utilizan a personajes como testimo- nios de que ya han adquirido los servicios que se anuncian y han conseguido cumplir sus objetivos.

\subsubsection{Valoraciones}

En cuanto a las valoraciones de escala (diferencial semántico 1-10), se han estudiado tres preguntas, que intentan conocer cuál es el objetivo de la campaña publicitaria y cómo realiza sus anuncios.

a) El anuncio induce al consumo. Por un lado, somos conscientes de que la publicidad en sí busca que el público consuma su producto o servicio, o potencie su consumo. Pero existen maneras más o menos objetivas para promocionar un producto, utilizando vías racionales o emocionales, aportando información u ofreciendo promesas. La media de las respuestas nos da 6,77. Esta cifra demuestra que existe una cierta mayoría cuyo objetivo principal es buscar la adquisición del servicio, mediante promesas.

b) Se limita a dar información. Esta cuestión busca conocer si el uso principal del anuncio es aportar información, para que el consumidor conozca en profundidad las propiedades del servicio y decida, de un modo más racional que emocional, si le interesa adquirir dicho servicio. En este caso, la media es de 5,03. Se trata de un término medio, donde las empresas emplean la mitad del anuncio para informar a los públicos y para dar argumentos a favor de la transparencia y de la confianza. En cambio, la otra mitad del anuncio es utilizada para justificar los beneficios.

c) Busca hacer la marca conocida. Existen otros casos, donde los anunciantes buscan notoriedad, es decir, dar a conocer la marca. Este es el primer paso (básico) para que el público adquiera el producto. Si no conocen la marca, difícilmente la comprarán. Por ello, la media de las empresas da un 4,93. Ello significa que una de las intenciones de las empresas es generar conocimiento por 
parte de los consumidores, para que luego decidan comprar sus servicios.

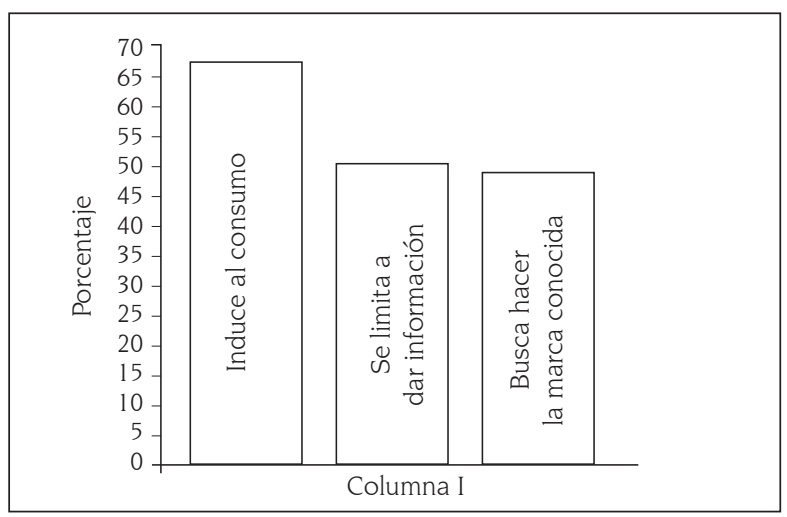

Fig. 2. Valoraciones

\subsubsection{Credibilidad y seducción}

Ante la pregunta de cómo aporta el anuncio credibilidad, nos encontramos con diversas respuestas. Primero, existen ciertas empresas de créditos fáciles que pertenecen a bancos nacionales e internacionales, como es el caso de BBVA y Banco Santander. Esto, a la vez que los distingue como los pocos bancos de reputación, genera credibilidad y confianza, ya que el posible consumidor depositará su confianza en algo que ya conoce y que tiene millones de usuarios en todo el mundo.

Además de esto, el hecho de indicar la información de contacto en caso de querer conocer mejor el servicio se convierte en un acto de transparencia, donde no hay nada que ocultar.

Otro elemento que genera credibilidad es el utilizado en el contexto de la pieza publicitaria, en referencia al uso de personajes testimonio, personajes famosos o el símil con artículos periodísticos. En este apartado nos referimos a aquellas personas que, por el hecho de ser famosas o por ser usuarias del servicio, proporcionan credibilidad en el receptor.

En cuanto a la seducción, observamos que los anuncios se centran más en aspectos informativos, de una manera persuasoria. Es decir, seducen a los públicos con frases que informan de los beneficios o promesas que ofrecen. Es el caso de "sin avales", "rápido", "fácil", "en 24 horas" o "sin comisiones". En otros ejemplos, la persuasión es más sutil, y consiguen transmitir valores como la facilidad de contratación, la comodidad, la inmediatez o la transparencia.

\subsection{Análisis connotativo}

\subsubsection{Tono y público}

En este apartado, analizamos, por un lado, el tono del anuncio, es decir, el estilo con el que la pieza publicitaria transmite el mensaje. Por otro lado, indicamos el público al que se dirige, ya que tono y público están relacionados.

En cuanto al tono, encontramos que el elemento más utilizado (50\%) es el de la informalidad, a través de un lenguaje estándar-coloquial. A menudo, este tono va acompañado de un estilo humorístico y cómico, o incluso familiar, que transmite al público la sensación de una marca alegre y cotidiana.

En el lado opuesto, y utilizada en el $40 \%$, se encuentra la emotividad, con la que el anuncio transmite el mensaje de un modo emocional. También suele relacionarse con la formalidad, en la que transmite un concepto serio y transparente, a la vez que comprensivo con el consumidor.

El tono cercano, utilizado en el 30\%, se puede encontrar tanto en un anuncio formal como en uno informal. Esto se debe a que, en una pieza formal, su seriedad conecta con el público y lo convierte en más cercano. En cambio, en una pieza humorística, el anuncio se convierte en un elemento informal que trata a los públicos como alguien cercano y que conoce desde hace años.

Otros tonos que aparecen en el análisis son menos utilizados, y suelen estar relacionados con 
los tonos que hemos explicado. Son los tonos alegre, directo, serio y racional (estos últimos, vinculados a un tono formal).

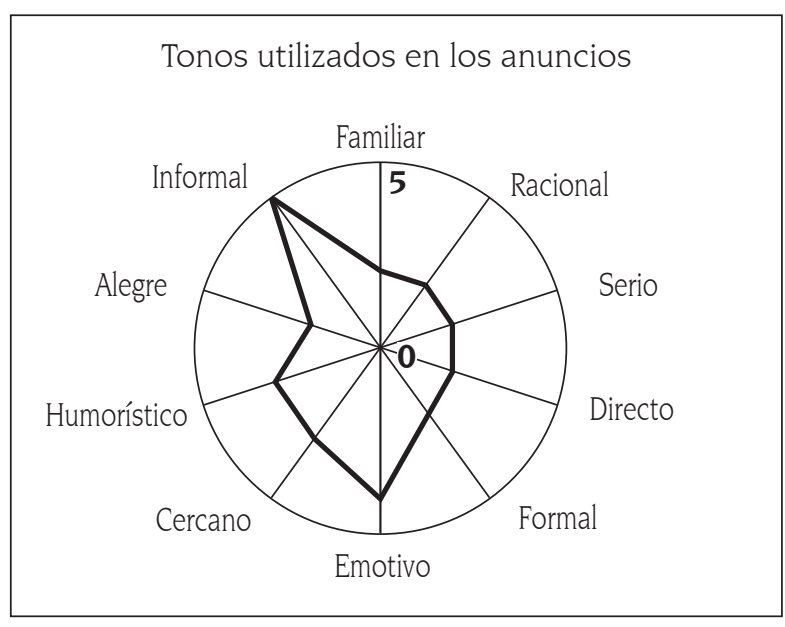

Fig. 3. Tonos utilizados en los anuncios

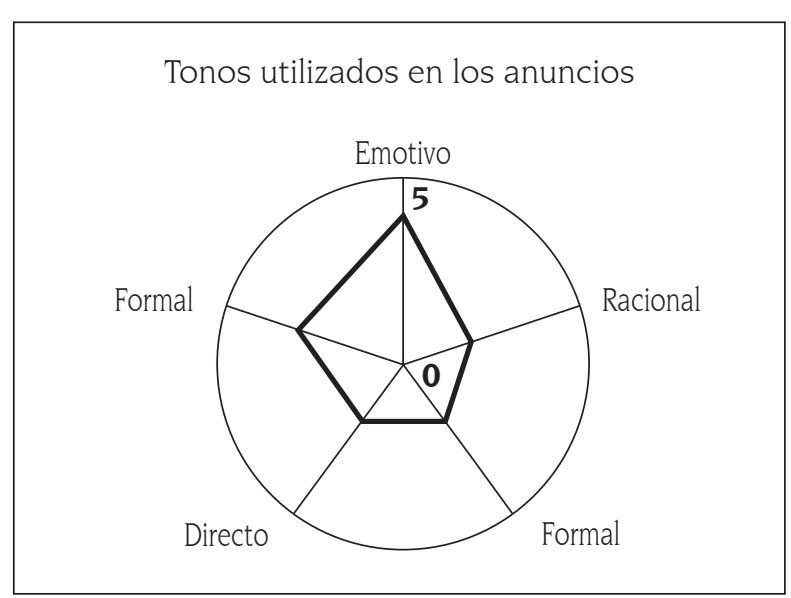

Fig. 4. Tonos utilizados en registro informal

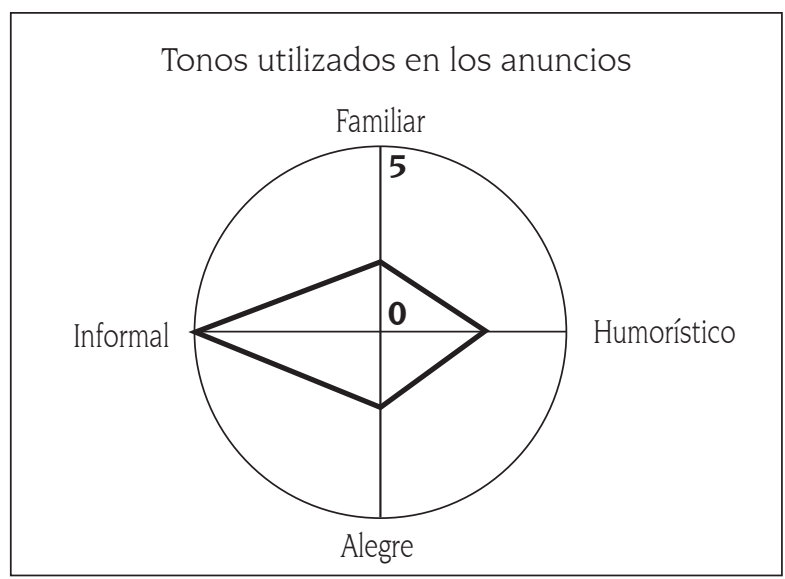

Fig. 5. Tonos utilizados en registro formal

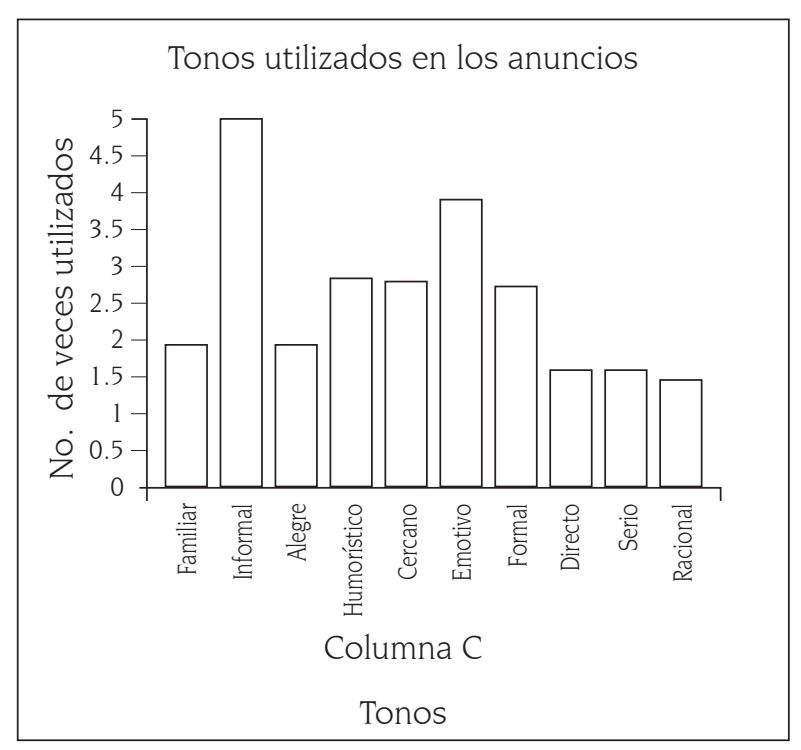

Fig. 6. Tonos utilizados en los anuncios.

En cuanto al público al que se dirigen los anuncios, encontramos un elemento común a la mayoría de piezas, y es que se dirigen a personas pertenecientes a una clase económica media-baja. Está claro que el servicio que estas empresas ofrecen se basa en un aspecto económico y, por tanto, es lógico que se dirija a sectores de la población necesitados de recursos económicos.

En cuanto a los individuos a los que se dirigen los anuncios, diferenciamos dos partes. Por un lado, encontramos a las mujeres, y a las madres en concreto. En este contexto podríamos incluir a las familias en sí, ya que el servicio se destina a satisfacer necesidades comunes a todos los integrantes de la familia.

Por otro lado, están los jóvenes. Éstos, al tratarse de un grupo que generalmente posee pocos recursos económicos, se convierten en el blanco perfecto para su publicidad.

\subsubsection{Valoraciones}

Este apartado pretende investigar las valoraciones que se han realizado (del 1 al 10), acerca de las ideas que transmiten los anuncios analizados. 
- Facilidad. Con una media cercana a 8, se comprueba que una de las claves de los anuncios de créditos fáciles se sustenta en la facilidad para adquirir sus servicios.

- Simplicidad. Junto con la facilidad, esta característica es indispensable para no poner inconvenientes a la hora de adquirir el servicio ofrecido.

- Comodidad. Este aspecto es similar a los dos elementos anteriores y cuantifica los problemas a los que se puede enfrentar el consumidor al contratar el servicio de crédito.

- Rapidez. Esta característica permite posicionar a las empresas, dirigiéndose a aquellas personas con unas necesidades económicas urgentes o inmediatas.

- Seguridad. Este elemento puede significar una barrera clara a la hora de contratar el servicio, pero no es la idea más transmitida en los anuncios, ya que posee una media de 5 .

- Seriedad y confianza. Estos tonos implicarán la sensación de seguridad y confianza, aunque no están muy explotados en la publicidad de los créditos (pues sólo tienen una media de 5 y 5,3, respectivamente).

- Transparencia. A modo de conclusión, observamos la poca claridad que transmiten los anuncios de créditos fáciles, ya que obtiene una valoración de menos de 5 .

- Ahorro de dinero. Con esta característica, nos referimos a si la publicidad está mostrando la idea de que, si se contratan los servicios ofrecidos, el consumidor ahorrará dinero. Con la respuesta obtenida, observamos que esta idea no está muy utilizada.

- Información completa. Ante la pregunta de si los anuncios dan la información completa o suficiente para conocer el servicio ofrecido, observamos la valoración más baja de todas las habidas, con una media de 3,07. Esto significa que el consumidor se queda con la sensación de que le falta información o que le están ocultando información esencial.
Si observamos el esquema de la figura 8, podemos comprobar que los tres pilares sobre los que se basan los anuncios de créditos fáciles son facilidad, simplicidad y comodidad. Aunque estos elementos son similares, son fundamentales para demostrar los beneficios básicos del crédito, ya que es en estas características donde se diferencian unos servicios de los otros. Así, estos elementos son los más importantes a la hora de transmitir en la publicidad, por ser los más valorados por los consumidores.

En un papel más secundario, existen otras ideas que también son valoradas. Se trata de confianza, seriedad, seguridad y ahorro de dinero, en este orden. Al parecer, son aspectos que no se transmiten tanto en la publicidad, quizá porque su importancia no es vital a la hora de contratar los servicios ofrecidos.

Finalmente, los dos últimos elementos están seleccionados a modo de conclusión. En primer lugar, el factor transparencia resume las características explicadas anteriormente. Y por lo observado, se percibe una falta de transparencia importante en los anuncios investigados. En segundo lugar, se comprueba que existe una falta de información grave o que no se puede acceder a toda la información esencial para conocer a fondo el servicio ofrecido.

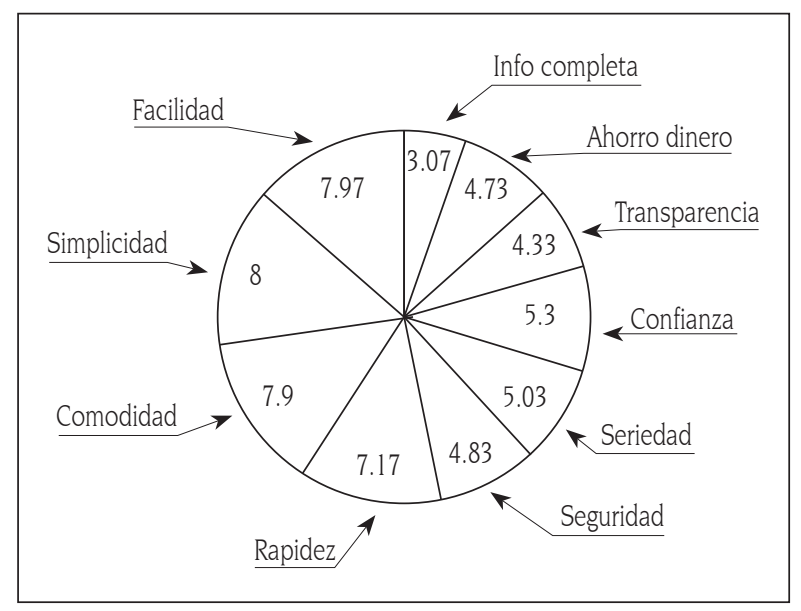

Fig. 7. Valoraciones 


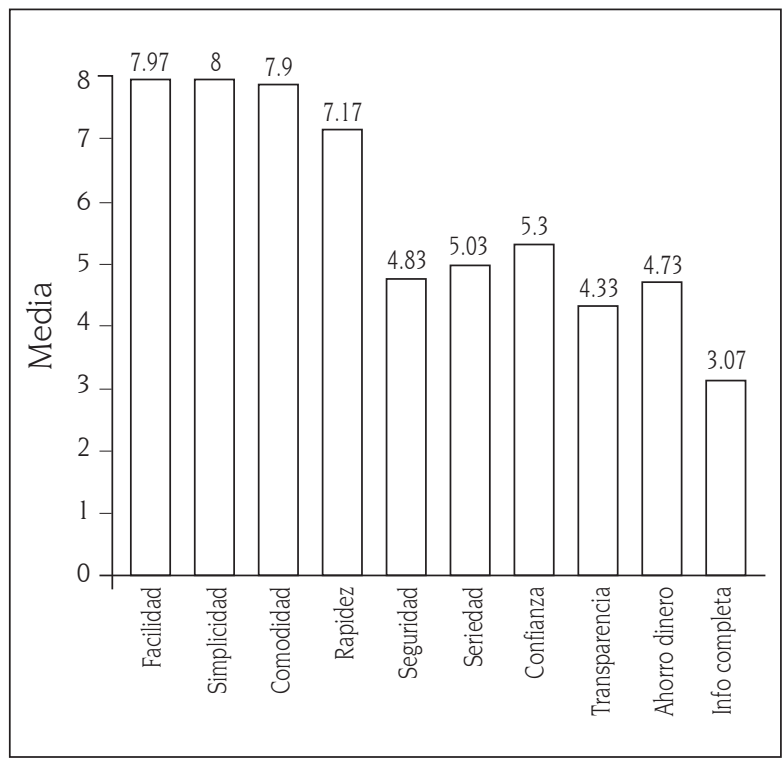

Fig. 8. Valoraciones

\section{CONCLUSIONES}

La publicidad puede ser analizada como un producto comunicativo dirigido a los posibles consumidores que transporta un mensaje elaborado a partir de la información y los intereses de la empresa anunciante. Pero no se limita a dar forma a la información del anunciante, sino que analiza sus objetivos, la comunicación de la competencia, investiga las motivaciones de los consumidores, y a partir de un conjunto de técnicas y su experiencia, propone al anunciante una serie de conceptos y una presentación creativa de los mismos para conseguir unos objetivos.

La publicidad, por lo tanto, no se puede desentender tan fácilmente del mensaje que elabora. Ello comporta la necesidad de un planteamiento ético de la actividad publicitaria.

En el conjunto de este análisis, hemos comprobado la importancia de la transparencia en la publicidad, a pesar de ser un aspecto muy criticado en la investigación. El problema más usual que encontramos en los anuncios es la falta de información, especialmente la información relati- va a las condiciones económicas (tipo de interés, consecuencias del incumplimiento de los pagos, garantías, etc.) Se trata de elementos que el consumidor debería tener en cuenta en el momento de formar y tomar una decisión.

En la actualidad, cuando una actividad comercial o industrial es legal, se puede realizar publicidad de la misma con el fin de informar y persuadir acerca de las ventajas y beneficios de sus productos o servicios. Pero en la publicidad analizada, y en buena parte de la publicidad relacionada con los servicios y productos financieros, se informa poco acerca de los aspectos económicos, limitándose a vender beneficios como la inmediatez para conseguir el crédito, la cuantía del préstamo que se puede obtener fácilmente, omitiendo, o dejando en segundo nivel, aspectos importantes y necesarios para poder tomar una decisión racional, puesto que la misma tiene consecuencias para el comportamiento económico de las personas, y una obligación ética y moral de la publicidad y las actividades económicas es no inducirles a error en sus decisiones de compra o adquisición de productos y servicios.

Paradójicamente, en la publicidad se ofrece una cuidada imagen de transparencia. Uno de los elementos más utilizados para transmitir transparencia es la cercanía con el receptor, a través del uso de personajes divertidos y testimonios o de situaciones cotidianas.

En cuanto al análisis publicitario, los conceptos más potenciados son los de rapidez y facilidad, y sólo unos pocos se distancian y consiguen un posicionamiento diferenciado.

Por tanto, observamos que la publicidad de los créditos de consumo al instante ofrece una serie de elementos para conseguir que las personas se interesen por estos productos. Estos elementos aportan valor para el emisor, y supuestos beneficios para las personas interesadas. Sin embargo, 
en la publicidad no aparece toda la información necesaria para que las personas puedan formarse una opinión y valoración correctas acerca de los aspectos positivos y negativos de los productos financieros, siendo la omisión uno de los aspectos más significativos. Esta omisión tiene su cabida porque legalmente hubo, hasta el año 2008 en España, una falta de regulación específica que, en garantía de los consumidores y usuarios, estableciera unos requisitos mínimos necesarios. Ahora bien, en un análisis de tipo ético, se puede observar que ello era necesario porque la omi- sión de información, entre otros elementos poco éticos, se realizaba consciente y voluntariamente porque favorecía los intereses de las empresas que ofrecían créditos al instante. El análisis de la publicidad específica de estos productos financieros ha permitido poner en evidencia que existen unos elementos y características específicos que han utilizado todas las empresas que se anunciaban, y entre ellos, la utilización consciente de una serie de argumentos -reclamos - que favorecen los intereses de unos, en detrimento de los intereses de los consumidores y usuarios. 